\title{
A rare renal involvement in a patient with axial Spondyloarthritis: don't miss focal segmental glomerulosclerosis and hyalinosis
}

\author{
Tbini Houssem ${ }^{1}$, Soumaya Boussaid ${ }^{1}$, ikram mami ${ }^{2}$, Sonia Rekik ${ }^{3}$, Lilia Ben Fatma ${ }^{1}$, \\ Samia Jemmali ${ }^{4}$, hela jebali ${ }^{2}$, hela Sahli $^{1}$, lamia rais $^{2}$, karim zouaghi ${ }^{2}$, and mohamed \\ elleuch $^{3}$ \\ ${ }^{1}$ Hôpital La Rabta \\ ${ }^{2}$ Department of Nephrology La Rabta Hospital, Tunis - Tunisia. \\ ${ }^{3}$ Hopital La Rabta \\ ${ }^{4}$ Universite de Tunis El Manar Faculte de Medecine de Tunis
}

November 7, 2021

\begin{abstract}
Renal involvement in spondyloarthritis is dominated by amyloidosis, IgA nephropathy and urolithiasis. Other nephropathies are rare. A patient followed for SpA consults with edema, hydrocele and a pleural effusion. A FSGS was confirmed by renal biopsy and the etiological investigation has ruled out the causes of secondary FSGS.
\end{abstract}

A rare renal involvement in a patient with axial Spondyloarthritis: don't miss focal segmental glomerulosclerosis and hyalinosis

Soumaya Boussaid ${ }^{1,3}$, Tbini Houssem ${ }^{1,3}$, Ikram Mami $^{2,3}$, Sonia Rekik ${ }^{1,3}$, Lilia Ben Fatma ${ }^{2,3}$, Samia Jammali ${ }^{1,3}$, Hela Jbali $^{2,3}$, Hela Sahli ${ }^{1,3}$, Lamia Rais ${ }^{2,3}$, Mohamed Karim Zouaghi ${ }^{2,3}$, Mohamed Elleuch ${ }^{1,3}$

${ }^{1}$ Rheumatology Department, Rabta Hospital, Tunis, Tunisia

${ }^{2}$ Nephrology, Dialysis and Renal Transplantation Department, Rabta Hospital, Tunis, Tunisia

${ }^{3}$ Faculty of Medicine of Tunis, University Tunis el Manar, Tunis, Tunisia

Authors' Affiliation:

Corresponding Author:

Tbini Houssem:

Doctor, Rheumatology department, la Rabta Hospital, Tunis, Tunisia

Adress: Rheumatology department, la Rabta Hospital,1007 Tunis, Tunisia

Mail: tbini.houssem@gmail.com

Phone: +21697627010

ORCID : https://orcid.org/0000-0001-9366-3193

Soumaya Boussaid: University Hospital Assistant, Rheumatology department, la Rabta Hospital, Tunis, Tunisia 
Mail : soumayaboussaid@hotmail.com

Sonia Rekik: Associate Professor, Rheumatology department, la Rabta Hospital, Tunis, Tunisia

Mail : rekik.sonia80@yahoo.fr

Samia Jemmali: University Hospital Assistant, Rheumatology department, la Rabta Hospital, Tunis, Tunisia

Mail :samia@jemmali.com

Hela Sahli: Professor, Rheumatology department, la Rabta Hospital, Tunis, Tunisia

Mail : sahlisrairihela@yahoo.fr

Mohamed Elleuch: Professor, Head of Rheumatology department, Rheumatology department, la Rabta Hospital, Tunis, Tunisia

Mail :medelleuch56@gmail.com

Ikram Mami: Associate Professor, Nephrology, Dialysis and Renal Transplantation Department, Rabta Hospital, Tunis, Tunisia

Mail :mami.ikram@live.fr

Lilia Ben Fatma Associate Professor, Nephrology, Dialysis and Renal Transplantation Department, Rabta Hospital, Tunis, Tunisia

Mail :liliabenfatma1@gmail.com

Hela Jbali : Associate Professor, Nephrology, Dialysis and Renal Transplantation Department, Rabta Hospital, Tunis, Tunisia

Mail :hela.bergaoui@yahoo.fr

Lamia Raies: Professor, Nephrology, Dialysis and Renal Transplantation Department, Rabta Hospital, Tunis, Tunisia

Mail :lamia.rais73@gmail.com

Mohamed Karim Zouaghi: Professor, Nephrology, Dialysis and Renal Transplantation Department, Rabta Hospital, Tunis, Tunisia

Mail :karim.zouaghi@fmt.rnu.tn

Key words:

Spondyloarthritis; Renal involvement; Focal segmental glomerulosclerosis and hyalinosis

Key Clinical Message:

Renal involvement in SpA should not be missed, screening these patients during follow-up allows early detection of any impairment and helps guide early nephroprotection and treatment measures. AA amyloidosis, IgA nephropathy and urolithiasis are the most reported, however, other rare involvement can be described.

\section{Author Agreement}

I, Tbini Houssem, here by certify that all named authors have seen and approved the final version of the manuscript being submitted. I on behalf of all authors warrant that the article is the authors' original work, hasn't received prior publication and isn't under consideration for publication elsewhere. I confirm that the order of authors listed in the manuscript has been approved by all of them. 
Authors understand that the Corresponding Author is the sole contact for the Editorial process. He is responsible for communicating with the other authors about progress, submissions of revisions and final approval of proofs.

\section{Conflict of Interest Declaration:}

Authors declare having no conflict of interest.

\section{Funding}

This research did not receive any specific grant from funding agencies in the public, commercial, or not-forprofit sectors.

\section{Authors'contribution :}

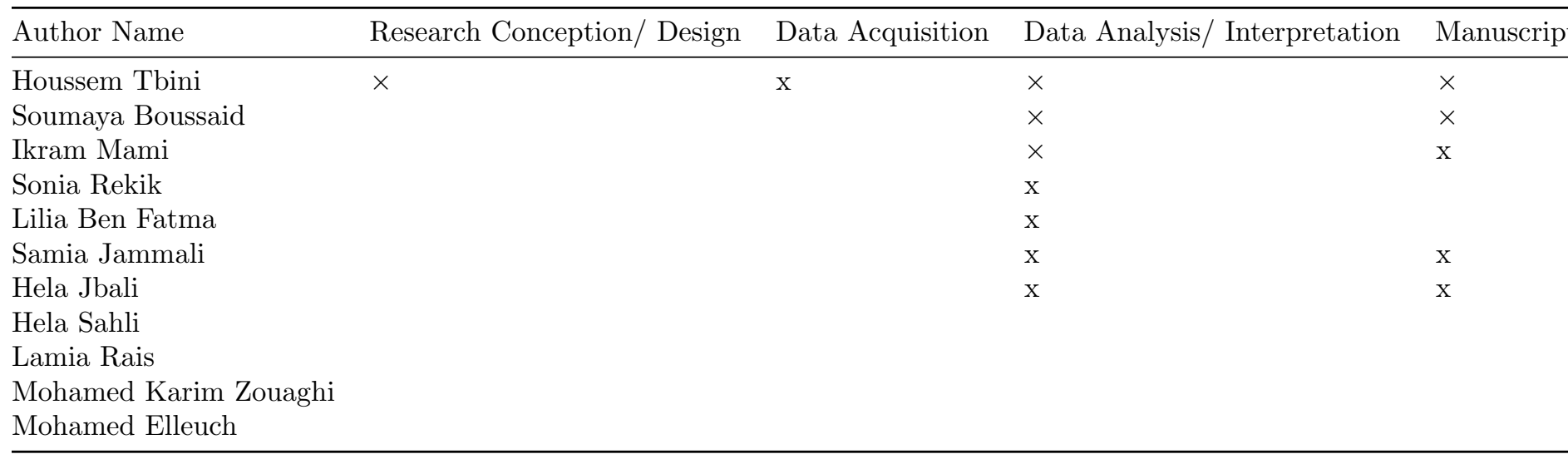

A rare renal involvement in a patient with axial Spondyloarthritis: don't miss focal segmental glomerulosclerosis and hyalinosis

Soumaya Boussaid ${ }^{1,3}$, Tbini Houssem ${ }^{1,3}$, Ikram Mami ${ }^{2,3}$, Sonia Rekik ${ }^{1,3}$, Lilia Ben Fatma ${ }^{2,3}$, Samia Jammali ${ }^{1,3}$, Hela $\mathrm{Jbali}^{2,3}$, Hela Sahli ${ }^{1,3}$, Lamia Rais ${ }^{2,3}$, Mohamed Karim Zouaghi ${ }^{2,3}$, Mohamed Elleuch ${ }^{1,3}$

${ }^{1}$ Rheumatology Department, Rabta Hospital, Tunis, Tunisia

${ }^{2}$ Nephrology, Dialysis and Renal Transplantation Department, Rabta Hospital, Tunis, Tunisia

${ }^{3}$ Faculty of Medicine of Tunis, University Tunis el Manar, Tunis, Tunisia

\section{Key Clinical Message:}

Renal involvement in SpA should not be missed, screening these patients during follow-up allows early detection of any impairment and helps guide early nephroprotection and treatment measures. AA amyloidosis, IgA nephropathy and urolithiasis are the most reported, however, other rare involvement can be described.

\section{Abstract}

Renal involvement in spondyloarthritis is rare and it is dominated by AA amyloidosis, IgA nephropathy and urolithiasis. Other nephropathies are rare and are limited to few case reports. Description of the case: we report a case of a patient followed for axial SpA who developed a focal segmental glomerulosclerosis and hyalinosis. Indeed, he consults after being lost to follow-up for 3 years with edema of the 2 lower limbs associated with a hydrocele and a bilateral pleural effusion of low abundance. A FSGS was confirmed by renal biopsy and the etiological investigation has ruled out the causes of secondary FSGS.Conclusion: Although renal involvement is rare in SpA, screening those patients in order to early detect any renal impairment is important during disease monitoring. 


\section{Key words:}

Spondyloarthritis; Renal involvement; Focal segmental glomerulosclerosis and hyalinosis

\section{Introduction:}

Spondyloarthritis $(\mathrm{SpA})$ is a chronic inflammatory rheumatism most commonly affecting young men. It is characterized by pelvic-spinal involvement which may be isolated or associated with peripheral joint and/or enthesitic involvement and by association with the human leukocyte antigen B27 (HLA-B27) haplotype (1).

Among the extra-articular manifestations of SpA, renal involvement is rare and mostly severe . AA amyloidosis, IgA nephropathy and urolithiasis are the most common causes. However, other nephropathies could be seen in SpA; they are rare and limited to case reports $(2,3)$. Thus, we report the case of a focal segmental glomerulosclerosis and hyalinosis (FSGS) in a patient with axial SpA.

\section{Case:}

A 49-year-old man with a history of retrobulbar optic neuritis was diagnosed with axial SpA since 2017. The diagnosis was made according to ASAS 2009 criteria (inflammatory chronic back pain over one year, positive C-Reactive-Protein (CRP) at $164 \mathrm{mg} / \mathrm{l}$ and bilateral sacroiliitis on X ray (grade II)) (4). There was no extra-articular manifestation at the time of the disease diagnosis. He was treated with Non-Steroidal Anti-Inflammatory Drugs NSAIDs (diclofenac and indomethacin) for a period of two months. This treatment was quickly stopped upon the discovery of proteinuria at $0.3 \mathrm{~g} / 24 \mathrm{~h}$. The patient was put on corticosteroid therapy (10 $\mathrm{mg}$ of Prednisone) and we decided to put him on biotherapy (Adalimumab).

The patient was lost to follow-up from 2017 to 2020. He consulted in December 2020 with edema of lower limbs, a hydrocele, and a bilateral pleural effusion of low abundance. His blood pressure was high (180-200 $\mathrm{mmHg}$ systolic). On osteoarticular examination, there were back stiffness and limitation in hips mobility. Moreover, there were no other articular involvement or abnormalities in the general examination.

Laboratory investigations showed: CRP at $51 \mathrm{mg} / \mathrm{l}$, normal level of urea and creatinine, the 24-hour urine protein was at $5.9 \mathrm{~g} / 24 \mathrm{~h}$, the proteinemia was at $46 \mathrm{~g} / \mathrm{l}$ and the albuminemia was at $14.4 \mathrm{~g} / \mathrm{l}$ and there was not hématuria. In front of those clinical and biological data; we retained the diagnosis of impure nephrotic syndrome with arterial hypertension. Regarding SpA activity, the Bath Ankylosing Spondylitis Disease Activity score (BASDAI) was at 6.3, the Ankylosing Spondylitis Disease Activity Score (ASDAS CRP) was at 4.95. By questioning the patient, he affirmed that he self-administrated paracetamol and NSAIDs occasionally in case of pain.

To explore the impure nephrotic syndrome, a renal biopsy was indicated and the anatomopathological examination concluded to a FSGS involvement (Figure 1). After ruling out the causes of secondary FSGS (human immune-deficiency virus, hepatitis B virus, parvovirus B19, and Cytomegalovirus infections, drug / toxic origin, adaptive FSGS by nephronic reduction and glomerular hyperfiltration) we put the patient on corticosteroid therapy (prednisone) at a dose of $1 \mathrm{mg} / \mathrm{kg} /$ day in association with diuretics (furosemide and spironolactone) and an ACE inhibitor (ramipril) for a period of 3 months, five albumin infusions were also prescribed.

After three months of treatment, the edema as well as the nephrotic syndrome have almost disappeared. Regarding his $\mathrm{SpA}$, the patient is currently awaiting a support agreement for Adalimumab from the social insurance funds. He only receives analgesic treatment.

\section{Discussion:}

$\mathrm{SpA}$ is a chronic inflammatory rheumatism predominantly affecting young men. Its prevalence is estimated between 0.3 and $2 \%$ of the general population (1). It can be responsible for axial, peripheral articular and enthesitic involvement.

Renal involvement is rare in SpA, its frequency varies between 4.3 and 35\%(2). This impairment is often underestimated because of its late onset (with an average of 6.6 to 19.4 years) (2) and the decrease in its 
incidence mainly explained by the reduction in the use of NSAIDs after the introduction of biotherapies in management of $\mathrm{SpA}(3)$.

The main circumstances of discovery of renal involvement during SpA are edema, proteinuria, hematuria, increased blood pressure, urolithiasis, deterioration of renal function and nephrotic syndrome $(2,5,6)$.

Data from the literature report renal involvement in SpA to three main etiologies represented by AA amyloidosis, IgA nephropathy and urolithiasis. These different etiologies vary according to studies. Ninety per cent of kidney damage are explained by amyloidosis (62\%) and IgA nephropathy (30\%) (2,5-7). Literature data on other etiologies (less than 8\%) are limited to case reports. Cases of extra-membranous glomerulonephritis, mesangial glomerulonephritis with $\mathrm{C} 3$ and IgM deposits, and membrano-proliferative glomerulonephritis have been reported rarely (8-11). Rare cases of SpA-FSGS association have also been reported, including 3 cases in 3 Tunisian series $(2,6,12,13)$. To the best of our knowledge, the present case is the fourth reported one with no other identifiable cause of secondary FSGS.

Given the paucity of data in the literature, it seems difficult to determine whether this association is etiological or a simple coincidence. In our patient, before adopting an association between SpA and FSGS, we excluded the causes of secondary FSGS (viral infections, drug / toxic origin, adaptive FSGS by nephronic reduction and glomerular hyperfiltration). Knowing that our patient had NSAIDs to control his SpA activity, the presence of FSGS could be either due to previous medication with NSAIDs or associated with his SpA.

A review of the literature showed that renal damage due to NSAIDs are mainly acute interstitial nephritis (AIN), acute tubular injury (ATI), minimal change disease (MCD), papillary necrosis (PN) and, rarely membranous nephropathy (MN) $(13,14)$. Literature data about the relationship between NSAIDs and FSGS are controversial, an association has been reported by some authors even in topical NSAIDs $(15,16)$. However Markowitz et al and Paueksakon et al in more recent study assert that available data do not support a relationship between NSAIDs and FSGS $(14,17)$. Those data may support that FSGS in our patient can be related to SpA. In summary, there is no study, as well as epidemiologic evidence, that directly demonstrate the causal relationship between SpA and FSGS. The role of NSAIDs, which are the main treatments for $\mathrm{SpA}$, as the cause of FSGS remains unclear. Since that, having eliminated the other possible causes is in favor of SpA and FSGS association.

Our patient will be put on Adalinumab. This later has been used since 2006 for the treatment of SpA (18). It has also been used in refractory cases of FSGS since 2014, it reduces proteinuria and protect kidney function from degradation, it has also been reported as an alternative in cases of resistance or allergy to rituximab in FSGS $(19,20)$.

\section{Conclusion:}

We report a rare case of FSGS in a patient with SpA. Recognition of renal impairment in SpA is important in order to guide necessary nephroprotection measures and appropriate therapy before significant renal damage occurs. The diagnosis should be made by renal biopsy which in the majority of cases reveals amyloidosis or IgA nephropathy, however, in rare cases, some rare associations can be discovered.

\section{References:}

1. Poddubnyy D, Rudwaleit M. Early spondyloarthritis. Rheum Dis Clin North Am. mai 2012;38(2):387-403.

2. Samia B, Hazgui F, Abdelghani KB, Hamida FB, Goucha R, Hedri H, et al. Atteinte renale au cours de la spondylarthrite ankylosante. Nephrologie Therapeutique. 1 juill 2012;8(4):220-5.

3. Lee S-H, Lee EJ, Chung SW, Song R, Moon J-Y, Lee S-H, et al. Renal involvement in ankylosing spondylitis: prevalence, pathology, response to TNF-a blocker. Rheumatol Int. juill 2013;33(7):1689-92.

4. Rudwaleit M, Landewe R, van der Heijde D, Listing J, Brandt J, Braun J, et al. The development of Assessment of SpondyloArthritis international Society classification criteria for axial spondyloarthritis (part 
I): classification of paper patients by expert opinion including uncertainty appraisal. Ann Rheum Dis. juin 2009;68(6):770-6.

5. Strobel ES, Fritschka E. Renal diseases in ankylosing spondylitis: review of the literature illustrated by case reports. Clin Rheumatol. 1998;17(6):524-30.

6. Ben Taarit C, Ajlani H, Ben Moussa F, Ben Abdallah T, Ben Maiz H, Khedher A. Les manifestations renales de la spondylarthrite ankylosante : a propos de 210 cas. Rev Medecine Interne. 1 dec 2005;26(12):9669 .

7. Cadinanos J, Costa R, Trujillo D, Real de Asua D. [Systemic secondary AA amyloidosis]. Med Clin (Barc). 1 avr 2015;144(7):324-30.

8. Shu KH, Lian JD, Yang YF, Lu Y, Wang JY, Lan JL, Chou G. Glomerulonephritis in ankylosing spondylitis. Clin Nephrol 1986;25: 169-71.

9. Swaak AJG, Frankfort I, Menon RS, Planten O, Pekelharing JM. Absence of IgA nephropathy in patients with ankylosing spondylitis. Rheumatol Int 1986;6:145-9.

10. Steisson K, Hirszel P, Weinstein A. Mesangial IgM nephropathy in a patient with HLA-B27 spondylarthropathy. Arthritis Rheum 1983;26: 1056.

11. Strobel ES, Fritschka E. Renal diseases in ankylosing spondylitis: review of the literature illustrated by case reports. Clin Rheumatol. 1998;17(6):524-30.

12. Frikha F, Kaddour N, Frigui M, Jallouli M, Marzouk S, Meftah S, et al. L'atteinte renale au cours de la spondylarthrite ankylosante. Rev Rhum. 1 nov 2006;73(10):1251.

13. Jones DW, Mansell MA, Samuell CT, Isenberg DA. Renal abnormalities in ankylosing spondylitis. Br J Rheumatol. oct 1987;26(5):341-5.

14. Paueksakon P, Fogo AB. Drug-induced nephropathies. Histopathology. 2017;70(1):94-108.

15. Artinano M, Etheridge WB, Stroehlein KB, Barcenas CG. Progression of minimal-change glomerulopathy to focal glomerulosclerosis in a patient with fenoprofen nephropathy. Am J Nephrol. 1986;6(5):353-7.

16. Andrews PA, Sampson SA. Topical non-steroidal drugs are systemically absorbed and may cause renal disease. Nephrol Dial Transplant. 1999;14(1):187-9.

17. Markowitz GS, Bomback AS, Perazella MA. Drug-induced glomerular disease: direct cellular injury. Clin J Am Soc Nephrol. 2015;10(7):1291-9.

18. Lapadula G, Marchesoni A, Armuzzi A, Blandizzi C, Caporali R, Chimenti S, et al. Adalimumab in the Treatment of Immune-Mediated Diseases. Int J Immunopathol Pharmacol. janv 2014;27(1_suppl):33-48.

19. Trachtman H, Vento S, Herreshoff E, Radeva M, Gassman J, Stein DT, et al. Efficacy of galactose and adalimumab in patients with resistant focal segmental glomerulosclerosis: report of the font clinical trial group. BMC Nephrol. 22 juill 2015;16:111.

20. Liu Y, Shi Y, Ren R, Xie J, Wang W, Chen N. Advanced therapeutics in focal and segmental glomerulosclerosis: Advanced therapeutics in FSGS. Nephrology. oct 2018;23:57-61. 


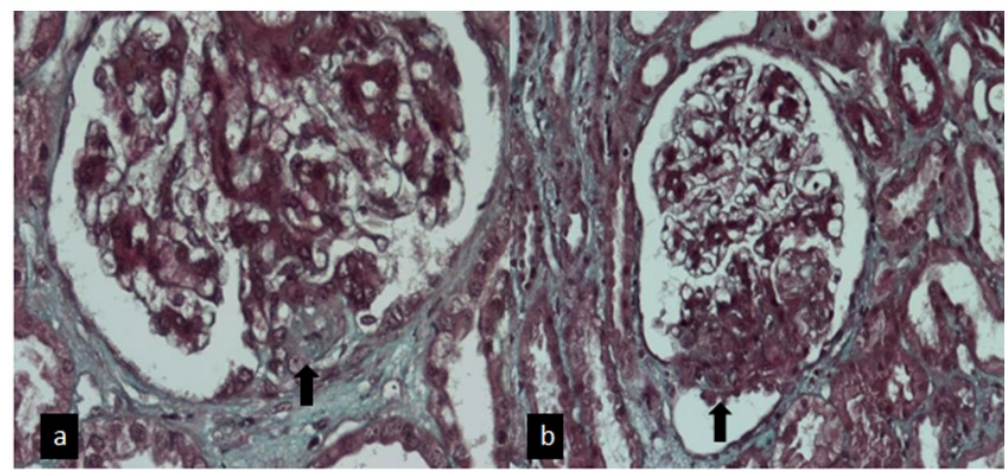

Figure 1. a: Glomerulus in a renal biopsy image with focal segmental glomerulosclerosis lesion (arrow). Light microscopy (Trichrome x 400); b: Glomerulus in a renal biopsy image with focal segmental glomerulosclerosis lesion (arrow). Light microscopy (Trichrome x 200) 